\title{
The synthesis and purification of amphiphilic conjugated donor-acceptor block copolymers
}

\begin{abstract}
Valerie D Mitchell ${ }^{1}$, Wallace WH Wong ${ }^{1}$, Mukundan Thelakkat $^{2}$ and David J Jones ${ }^{1}$
Nanoscale domains of donor and acceptor materials are crucial for charge generation in organic photovoltaic devices. These domains are difficult to achieve reproducibly in blended materials, but could be engineered into single-material active layers composed of donor-acceptor block copolymers (BCPs). In this work, we report the synthesis and purification of two novel fully conjugated BCPs, P3HT- $b-$ PF $_{\mathrm{TEG}}$ TBT and P3HT- $b-\mathrm{PF}_{\mathrm{TEG}} \mathrm{T6BT}$. To enhance phase separation and self-assembly, these two polymers incorporate tetraethylene glycol side chains into the PFTBT acceptor block, generating an amphiphilic system. The chemical disparity of the donor and acceptor blocks allowed the development of a purification strategy capable of isolating the desired BCP from homopolymer contaminants. This is a significant improvement over previous systems in which homopolymer contaminants can dominate the reaction mixture, affecting performance and morphology. We show that preliminary morphological analysis indicates spontaneous phase separation in thin films, demonstrating the efficacy of this design strategy and the potential application of these materials in organic photovoltaic devices.
\end{abstract}

Polymer Journal (2017) 49, 155-161; doi:10.1038/pj.2016.97; published online 19 October 2016

\section{INTRODUCTION}

Bulk heterojunction organic photovoltaics (OPVs) could provide a source of renewable energy that is inexpensive and printable on flexible substrates via roll-to-roll processes. This technology would supplement the bulky, rigid modules of traditional silicon PV with a cheap, highly portable alternative. The field of OPV research has developed significantly over the past 15 years, with power conversion efficiencies increasing from $2.5 \%$ in $2001^{1}$ to $11.5 \%$ in $2016 .^{2}$ However, the transfer from laboratory to industry has yet to be fully realized. For this reason, new approaches to material design and optimization must be investigated with a focus on key industrial factors such as increased solvent processability, stability and reproducibility in addition to efficiency. ${ }^{3,4}$

In OPV, absorption of light does not generate free charges directly. Instead, a coulombically-bound charge pair termed an exciton is created. Excitons require an additional input of energy if they are to undergo charge separation into free charges, and this is accomplished through combining materials with differing electron affinities together in a thin film. The energetic offset leads to preferential segregation of the electron into the acceptor material and the hole into the donor material. Control of donor/acceptor domain sizes is crucial for OPV efficiency because charge separation occurs at the interface between donor and acceptor, and because the distance that an exciton can diffuse during its lifetime is around $10 \mathrm{~nm} .{ }^{5}$ Ideal domain sizes are between 10 and $20 \mathrm{~nm},{ }^{6}$ small enough that most excitons can reach an interface, but large enough to minimize recombination between the free charges.
The most common method of obtaining these domains is through blending the donor and acceptor materials and co-depositing them onto a chosen electrode. Often subsequent processing steps such as thermal annealing ${ }^{7,8}$ or solvent vapor annealing 9,10 are used to encourage partial phase separation. The resultant morphologies are difficult to control and maintain, and small variations in technique and material can lead to suboptimal domain sizes. ${ }^{11}$ For example, it has been shown that simply operating solar cells composed of blended materials generates enough heat to induce further phase separation and detrimentally increase domain sizes in semicrystalline materials. ${ }^{12}$ This hinders application of these materials in industry where reproducibility and stability are crucial. In addition, a key advantage of OPV is the solution processability of these materials. However, in these blended materials, the choice of solvent is restricted to those that can accommodate both components to some threshold level. To date, this most often dictates the use of chlorinated and toxic solvents that are disadvantageous for industrial applications, ${ }^{13}$ although there have been recent advances in the use of non-chlorinated aromatic solvents such as mesitylene and anisole. ${ }^{14,15}$

One alternative to this blending approach is the covalent linkage of donor and acceptor material into a single entity. Ideally in such a system, the donor and acceptor units will self-assemble into domains in the order of the size of the individual components, therefore to achieve $10 \mathrm{~nm}$ domains, the materials must necessarily be polymeric. Previous work on molecular donor-acceptor materials produced only modest power conversion efficiencies, a result attributed to a loss of charge carriers to recombination within the overly small domains. ${ }^{16}$

${ }^{1}$ School of Chemistry, University of Melbourne, Bio21 Institute, Parkville, VIC, Australia and ${ }^{2}$ Applied Functional Polymers, Department of Macromolecular Chemistry I, University of Bayreuth, Bayreuth, Germany

Correspondence: Dr DJ Jones, School of Chemistry, University of Melbourne, Bio21 Institute, 30 Flemington Road, Parkville, Victoria 3010, Australia.

E-mail: djjones@unimelb.edu.au

Received 30 June 2016; revised 3 August 2016; accepted 10 August 2016; published online 19 October 2016 


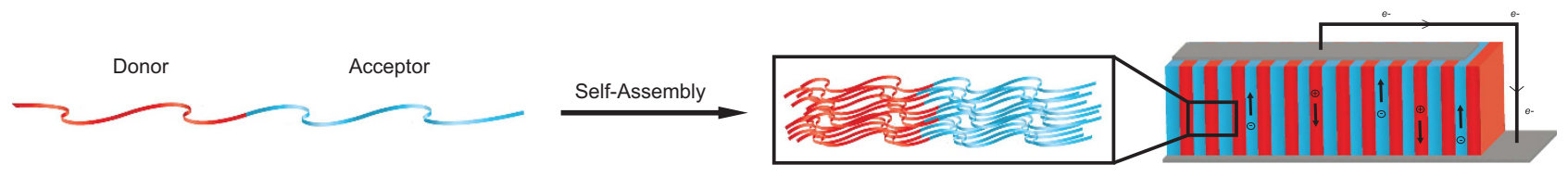

Figure 1 Schematic of proposed block copolymer self-assembly into lamellar active layer morphology.

Although there has been extensive work on block copolymers (BCPs) that employ pendant chromophores on a nonconjugated backbone, ${ }^{17-21}$ to maximize chromophore density, the polymers should be fully conjugated. For these reasons, fully conjugated BCPs are the subject of this investigation.

Within these constraints, material design is freed from balancing the solubilities of the two-component system. Rather, the solubility of the donor-acceptor pair can be tuned through modification of a single component, for example, incorporating hydrophilic side chains into the donor or acceptor polymer will increase the solubility of the pair in polar solvents. The covalent linkage of donor and acceptor physically prohibits the separation of the two materials into overly large domains. Rather than trying to attain metastable partial phase separation as in blends, in BCP systems, the optimal morphology is obtained when the materials obtain complete phase separation into well-defined domains. Although BCPs with flexible backbones can adopt a variety of morphologies depending on the composition, fully conjugated BCPs are more rigid and so tend to adopt lamellar morphologies. ${ }^{22}$ If properly oriented perpendicular to the electrode substrate, these lamellae could provide excellent charge percolation pathways, ideal for OPV function. The application of this envisioned morphology in an organic photovoltaic is depicted in Figure 1.

Although BCPs provide a well-controlled route to a theoretically ideal morphology, obtaining clean phase separation in fully conjugated materials has proven to be a challenge. The highest performing example of this strategy to date achieved a power conversion efficiency of $3.1 \%$ employing poly(3-hexylthiophene) (P3HT) as the donor material and poly $\left(2,7-\left(9^{\prime}, 9^{\prime}\right.\right.$-dioctylfluorene $)$-alt-5,5-(4', $7^{\prime}$-di-2-thienyl-2', $1^{\prime}, 3^{\prime}$-benzothiadiazole) (PFTBT) as the acceptor material in the BCP P3HT- $b$-PFTBT (Figure $2 \mathrm{a}, \mathrm{R}=\mathrm{H}$ ). ${ }^{13}$ The authors observed phase separation into $9 \mathrm{~nm}$ domains in this system, which may have contributed to the high performance. However, in a subsequent investigation of 30 closely related P3HT- $b$-PFTBT BCP derivatives, little or no phase separation was obtained regardless of processing conditions. ${ }^{23}$ This supports previous work carried out on P3HT$b$-PFT6BT (Figure 2a, $\mathrm{R}=\mathrm{C}_{6} \mathrm{H}_{13}$ ), in which no phase separation was observed. ${ }^{24}$ The researchers in both projects attributed the lack of phase separation to the incorporation of solubilizing alkyl side chains on the PFTBT acceptor materials, and hypothesized that additional alkyl chains led to an increased miscibility of the donor and acceptor. The poor morphologies led to a drastic decrease in OPV performance.

The degree of phase separation in BCPs can be predicted by the Flory-Huggins segment-segment interaction parameter $\chi \cdot^{25}$ This parameter balances the energetic cost of the two blocks interacting with each other against the cost of them interacting with themselves. As the interaction between the two blocks becomes less energetically favorable, the value of $\chi$ increases and microphase separation becomes more likely, and this effect intensifies as the polymer chain length grows. Once the product of $\chi$ and the number of monomers per chain $(N)$ exceeds 10.5 , phase separation is favored. ${ }^{26}$ Thus, when designing BCP materials, introducing dissimilarity between segments increases the likelihood of obtaining pure domains. a P3HT- $b$-PFT(X)BT

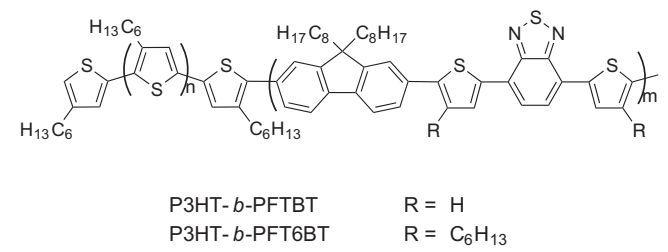

b

P3HT- $b-P F$ TEG T(X)BT

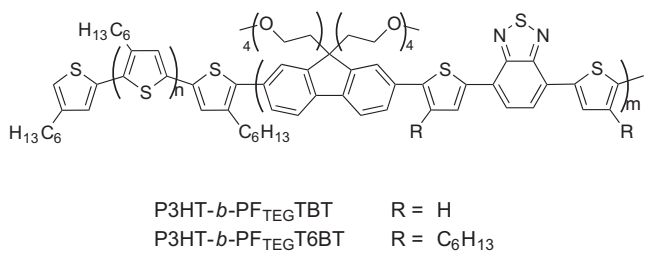

Figure 2 Structures of previously reported block copolymers (a) and their amphiphilic analogs (b).

In this work, we report the synthesis of two new polymers based on the P3HT- $b$-PFTBT scaffold. The materials differ from previous work, in that, hydrophilic tetraethylene glycol side chains were incorporated into the PFTBT material to generate two novel amphiphilic BCPs. Although there is some literature precedence for the synthesis of amphiphilic BCPs, this strategy has not yet been applied to highperformance OPV materials. ${ }^{27}$ Tetraethylene glycol was chosen for its ability not only to confer hydrophilicity, but also its demonstrated capacity to increase the dielectric constant of organic materials, thereby enhancing exciton dissociation. ${ }^{28}$ This rational design is expected to produce materials with enhanced solubility, microphase separation, morphological reproducibility and photovoltaic performance over existing organic photovoltaic active layers.

\section{EXPERIMENTAL PROCEDURE}

Unless otherwise noted, all materials were reagent grade and used as received without further purification. Anhydrous tetrahydrofuran, toluene, dichloromethane and ether were dried using alumina columns. Additional information including measurement details and complete synthetic procedures are given in the Supplementary Information.

The synthetic procedure used to prepare $\mathrm{P} 3 \mathrm{HT}-b-\mathrm{PF}_{\mathrm{TEG}} \mathrm{T}(\mathrm{R}) \mathrm{BT}$ is shown in Scheme 1. All monomers were prepared according to literature procedures, the details of which are presented in the Supplementary Information. The BCPs and isolated acceptor polymers were prepared via Suzuki polycondensation in the presence and absence, respectively, of a poly(3-hexylthiophene) macroinitiator as described below.

\section{Synthesis of $\mathrm{PF}_{\mathrm{TEG}} \mathrm{T}(\mathrm{R}) \mathrm{BT}$ acceptor polymer}

In a general procedure, Compound $\mathbf{2}(0.1 \mathrm{mmol})$, Compound $\mathbf{3}(0.09 \mathrm{mmol})$, toluene $(5 \mathrm{ml})$, tetraethylammonium hydroxide ( $20 \%$ aqueous solution, $1 \mathrm{ml}$ ) and Aliquat 336 ( 1 drop) were combined in a Schlenk tube and bubbled with 


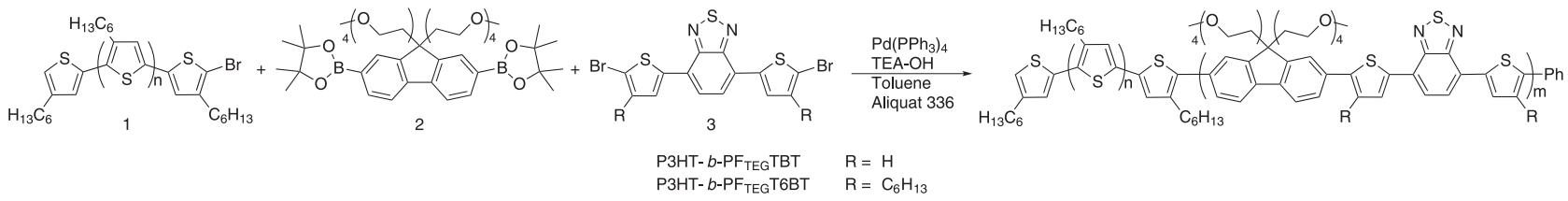

Scheme 1 Synthesis of fully conjugated block copolymers via Suzuki polycondensation. TEA-OH, tetraethylammonium hydroxide solution (20\% in $\mathrm{H}_{2} \mathrm{O}$ ),

Table 1 Molecular weights and yields of syntheses

\begin{tabular}{|c|c|c|c|c|}
\hline & $\mathrm{M}_{n}\left(\mathrm{~kg} \mathrm{~mol}^{-1}\right)$ & PDI & P3HTa (\%) & Yield (\%) \\
\hline Р3НТ & 17.8 & 1.1 & & 51 \\
\hline P3HT- $b-$ PF $_{\mathrm{TEG}}$ TBT & $42.1(41.3)^{b}$ & 1.9 & 42 & 17 \\
\hline $\mathrm{PF}_{\mathrm{TEG}} \mathrm{TBT}$ & 15.1 & 2.1 & & 87 \\
\hline P3HT & 17.6 & 1.1 & & 41 \\
\hline P3HT- $b-\mathrm{PF}_{\mathrm{TEG}} \mathrm{T6BT}$ & $37.3(48)^{b}$ & 1.9 & 47 & 26 \\
\hline $\mathrm{PF}_{\mathrm{TEG}} \mathrm{T} \mathrm{BT}$ & 30.5 & 2.1 & & 84 \\
\hline
\end{tabular}

Abbreviation: GPC, gel permeation chromatography.

aCalculated from GPC $M_{\mathrm{n}}$.

${ }^{\mathrm{b}}$ As determined by integration of ${ }^{1} \mathrm{H}$ NMR backbone signals.

$M_{\mathrm{n}}$ and PDI determined from GPC.

nitrogen for $15 \mathrm{~min}$. The catalyst $\mathrm{Pd}\left(\mathrm{PPh}_{3}\right)_{4}(11.5 \mathrm{mg}, 0.01 \mathrm{mmol})$ was added to the mixture and bubbled with nitrogen for an additional $5 \mathrm{~min}$. The reaction vessel was sealed and heated to $90{ }^{\circ} \mathrm{C}$ with stirring overnight. The polymer was endcapped by adding phenylboronic acid in toluene $(20.4 \mathrm{mg}, 0.1 \mathrm{mmol})$ via syringe and stirring for an additional $4 \mathrm{~h}$ before the reaction was allowed to come to room temperature. Chloroform and water were added, the organic phase was collected and precipitated in methanol to yield the product. The polymer was collected and purified using Soxhlet extraction in methanol, petroleum spirits and finally chloroform. Synthetic yields and molecular weights are given in Table 1 , whereas ${ }^{1} \mathrm{H}$ nuclear magnetic resonance (NMR) spectroscopic characterization is given in the Supplementary Information.

\section{Synthesis of P3HT- $b-\mathrm{PF}_{\mathrm{TEG}} \mathrm{T}(\mathrm{R}) \mathrm{BT} \mathrm{BCP}$}

Compound 1 (500 mg, $\left.0.026 \mathrm{mmol}, 19.19 \mathrm{~kg} \mathrm{~mol}^{-1}\right)$, Compound 2 $(0.52 \mathrm{mmol})$, Compound $3(0.52 \mathrm{mmol})$, toluene $(25 \mathrm{ml})$, tetraethylammonium hydroxide (20\% solution, $5 \mathrm{ml}$ ) and Aliquat 336 ( 1 drop) were combined in a Schlenk tube and bubbled with nitrogen for $15 \mathrm{~min}$. The catalyst $\mathrm{Pd}\left(\mathrm{PPh}_{3}\right)_{4}$ ( $57.75 \mathrm{mg}, 0.05 \mathrm{mmol}$ ) was added to the mixture and bubbled with nitrogen for an additional $5 \mathrm{~min}$. The reaction vessel was sealed and heated to $90^{\circ} \mathrm{C}$ with stirring for $24 \mathrm{~h}$. The polymer was endcapped by adding phenylboronic acid (53 mg, $0.1 \mathrm{mmol}$ ) in $2 \mathrm{ml}$ of degassed toluene and heating at $90^{\circ} \mathrm{C}$ for $3 \mathrm{~h}$, followed by $30 \mu \mathrm{l}$ of bromobenzene and stirring for an additional $3 \mathrm{~h}$. The reaction was allowed to come to room temperature. Chloroform and water were added, and the organic phase was collected and precipitated in methanol to yield the product mixture. The polymer was collected, dissolved in chloroform and adsorbed onto $45 \mathrm{ml}$ of silica gel. The silica was then washed with chloroform to remove unreacted P3HT, dichloromethane/methanol (9:1) to remove $\mathrm{PF}_{\mathrm{TEG}} \mathrm{T}(\mathrm{R}) \mathrm{BT}$ impurities and finally chloroform/methanol $(9: 1)$ to afford the BCP. Synthetic yields and molecular weights are given in Table 1, whereas ${ }^{1} \mathrm{H}$ NMR characterization is given in the Supplementary Information.

\section{RESULTS AND DISCUSSION}

The synthetic strategy employed to generate the fully conjugated amphiphilic BCPs P3HT- $b-\mathrm{PF}_{\mathrm{TEG}} \mathrm{TBT}$ and P3HT- $b$ - $\mathrm{PF}_{\mathrm{TEG}} \mathrm{T} 6 \mathrm{BT}$ followed a procedure first developed by $\mathrm{Ku}$ et al. ${ }^{29}$ in 2012 . The P3HT block was prepared through Grignard metathesis polymerization that is known to produce polymers with well-defined molecular weight and a single bromine terminus that can be used in further condensations. ${ }^{30}$ Addition of the P3HT-Br macroinitiator to a Suzuki polycondensation reaction between fluorene and dithienobenzothiadiazole monomers 2 and 3 resulted in chain extension to form the desired BCP (Scheme 1). This synthetic approach necessarily generates a mixture of products, including unreacted $\mathrm{P} 3 \mathrm{HT}, \mathrm{PF}_{\mathrm{TEG}} \mathrm{T}(\mathrm{R}) \mathrm{BT}$ homopolymer, as well as diblock and triblock copolymers. Typical purification methods for these syntheses have employed Soxhlet extraction or preparative gel permeation chromatography (GPC) for purification, however, both of these techniques are nonspecific in the species isolated. For example, P3HT- $b$-PFTBT ${ }^{13}$ was purified using a series of Soxhlet extractions in acetone, hexanes and finally chloroform to afford the product. However, none of the polymeric species are soluble in acetone and hexanes, whereas all are soluble in chloroform, and so this technique is incapable of isolating the BCP specifically. It has been demonstrated in extensively studied nonconjugated BCP systems that homopolymer impurities can have a drastic effect on the morphological behavior of these materials. The incorporation of a homopolymer into the BCP assembly is dependent on the stretching energy of the polymers, and if unsuccessful can lead to phase separation into homopolymer rich domains and BCP domains. ${ }^{31}$ For example, a $4 \%$ increase in homopolymer volume fraction in a $\mathrm{BCP} /$ homopolymer blend led to the elimination of a lamellar morphology in favor of a polymeric microemulsion, and with an additional $2 \%$ homopolymer, a two-phase system of homopolymer riddled with BCP aggregates was seen. ${ }^{32}$ Fully conjugated BCP phase behavior is much less studied, and so these lessons from classical BCP systems may not translate directly, however, they indicate the complexities of blended systems. It is expected that precise control over BCP morphologies will be more easily obtained in a pure $\mathrm{BCP}$ system. In addition, an intriguing aspect of these BCPs is that the interface between donor and acceptor is defined covalently and so allows rational design for optimized charge transfer. ${ }^{33,34}$ Homopolymer contaminants dilute this capability. Despite these considerations, difficulties with purification have meant that analysis of fully conjugated BCPs has typically involved polymeric mixtures. A recent report found that out of a synthesis of $30 \mathrm{BCPs}$, the percentage of diblock copolymer in the reaction mixtures ranged from $33-64 \% .{ }^{23}$ In the amphiphilic BCP system under investigation, however, the differing solubilities of the homopolymers can be exploited to facilitate purification.

\section{Macroinitiator purification}

For this work, the purification began with the P3HT macroinitiator. This was accomplished through successive Soxhlet extractions of the P3HT material in acetone, petroleum ether and dichloromethane to remove all lower molecular weight material. A final chloroform rinse recovered the desired $\mathrm{P} 3 \mathrm{HT}$ macroinitiator. The $\mathrm{PF}_{\mathrm{TEG}}$ TXBT acceptor materials are readily soluble in dichloromethane, and so ideally the $\mathrm{P} 3 \mathrm{HT}$ would be insoluble in dichloromethane to allow differentiation between the species. 


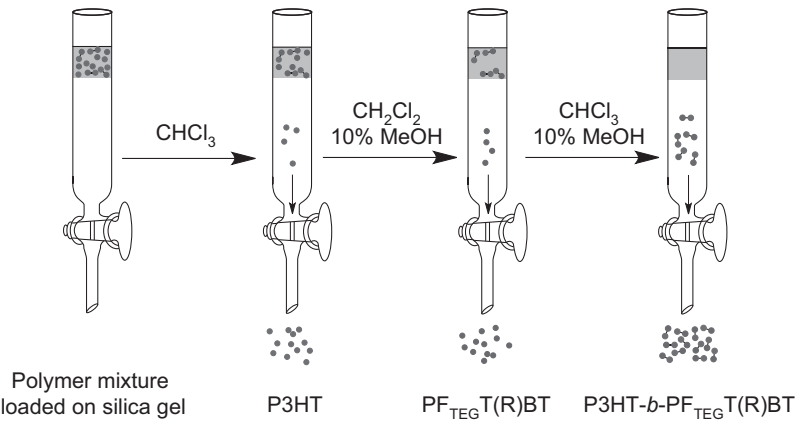

Figure 3 Block copolymer purification strategy. A full color version of this figure is available at the Polymer Journal journal online.

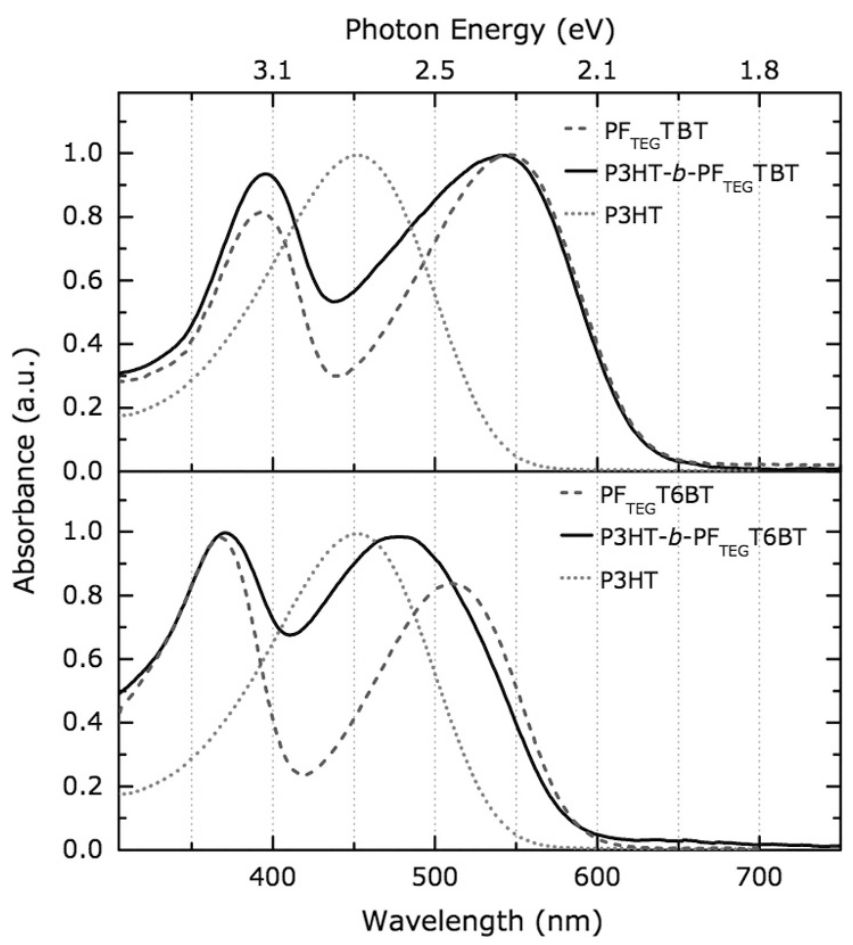

Figure 4 UV/Vis spectra of block copolymers and their constituent homopolymers in solution. UV, ultraviolet; Vis, visible. A full color version of this figure is available at the Polymer Journal online.

\section{BCP purification}

Addition of the purified P3HT-Br macroinitiator to the Suzuki polycondensation reaction, described in Scheme 1, generated the desired BCP as well as the other expected polymeric contaminants. The crude reaction mixture was then adsorbed on an excess of silica gel. The tetraethylene glycol moieties on the $\mathrm{PF}_{\mathrm{TEG}} \mathrm{TBT}$ polymers bind more tightly to the silica than $\mathrm{P} 3 \mathrm{HT}$, thus simply washing the silica with chloroform removes the unreacted macroinitiator. Because P3HT- $b$ - PF $_{\text {TEG }}$ TBT- $b$-P3HT triblock copolymers are dominated by the solubility of $\mathrm{P} 3 \mathrm{HT}$, these too are removed in the chloroform wash (see discussion below). The addition of methanol to the eluent disrupts the strong association of the tetraethylene glycol moieties and washing the silica gel with $10 \%$ methanol in dichloromethane removes the $\mathrm{PF}_{\mathrm{TEG}} \mathrm{TBT}$ homopolymer. Because the $\mathrm{P} 3 \mathrm{HT}$ macroinitiator employed in the BCP is not soluble in dichloromethane by design, only a small amount of BCP is lost in this wash. Finally, washing with $10 \%$ methanol in chloroform affords the BCP with a minimum amount of polymeric contaminants, as depicted in Figure 3.

Analysis of the washes using GPC in conjunction with a multiwavelength detector reveals the efficacy of the purification technique. In solution, PFTBT-based materials have characteristic absorption maxima in the $360 \mathrm{~nm}$ range, whereas $\mathrm{P} 3 \mathrm{HT}$ absorbs most strongly at $450 \mathrm{~nm}$ (Figure 4). By analyzing GPC results at these two wavelengths, the composition of the fractions can be inferred. In Figure 5, it can clearly be seen that the chloroform washes are predominantly unreacted P3HT macroinitator as well as triblock copolymer. The dichloromethane/methanol washes absorb more strongly at $360 \mathrm{~nm}$, indicating a higher concentration of PFTBT homopolymers. The chloroform/methanol wash, in contrast, has equal absorption at 450 and $360 \mathrm{~nm}$, and is clearly shifted to molecular weights roughly double that of the P3HT macroinitiator. The three fractions from each block copolymerization were collected and analyzed, and the relative compositions of the crude mixtures are summarized in Table 2. The yields of the polymer mixture before purification were 85 and $82 \%$ for P3HT- $b$ - PF $_{\text {TEG TBT }}$ and $\mathrm{P} 3 \mathrm{HT}-b-\mathrm{PF}_{\mathrm{TEG}} \mathrm{T} 6 \mathrm{BT}$, respectively. After separation, the majority contaminant in both polymerizations was $\mathrm{P} 3 \mathrm{HT}$, however, the percent of the crude mixture comprised of $\mathrm{P} 3 \mathrm{HT}$ is $20 \%$ higher in the P3HT- $b-\mathrm{PF}_{\mathrm{TEG}} \mathrm{TBT}$ reaction at the expense of BCP formation that decreased by $10 \%$. The increase in $\mathrm{P} 3 \mathrm{HT}$ contamination in $\mathrm{P} 3 \mathrm{HT}-b-\mathrm{PF}_{\mathrm{TEG}} \mathrm{TBT}$ can be ascribed to the higher degree of triblock copolymer formed as clearly seen in the GPC trace (Figure 5a). Although triblock formation is always possible, it is not favored owing to the low concentration of active P3HT end-groups relative to acceptor monomers. However, in $\mathrm{P} 3 \mathrm{HT}-b-\mathrm{PF}_{\mathrm{TEG}} \mathrm{TBT}$, the fluorene monomer is very soluble and can add quickly to the $\mathrm{P} 3 \mathrm{HT}$-Br, whereas the 4,7-dibromo-2,1,3-dithienobenzothiadiazole (TBT) monomer is only poorly soluble and so struggles to add at a comparable rate. This decreased reaction rate increases the likelihood that a P3HT-Br will encounter the reactive boronic acid terminus of the growing $\mathrm{BCP}$. In contrast, the addition of solubilizing hexyl side chains to the TBT unit in P3HT- $b$ - $\mathrm{PF}_{\mathrm{TEG}} \mathrm{T} 6 \mathrm{BT}$ increases the monomer's solubility and markedly reduces the amount of triblock copolymer produced. Although the percentages of BCP present in the crude polymer mixtures are low (21 and 32\%), they are not unreasonable when compared with previous reports for this type of BCP synthesis ${ }^{23,35}$ and emphasize the value of a purification technique capable of isolating the $\mathrm{BCP}$ product.

The molecular weights of the resultant BCPs and the corresponding homopolymers are summarized in Table 1 . GPC of the P3HT- $b$ $\mathrm{PF}_{\mathrm{TEG}} \mathrm{TBT}$ and $\mathrm{P} 3 \mathrm{HT}-b-\mathrm{PF}_{\mathrm{TEG}} \mathrm{T} 6 \mathrm{BT}$ polymers indicates that they are 42 and $47 \%$ P3HT by weight, respectively. Molecular weights were also estimated through the integration of ${ }^{1} \mathrm{H}$ NMR signals corresponding to the donor and acceptor, and are given in parentheses in Table 1. These values are in reasonable agreement with GPC data, although they suggest a lower P3HT fraction. This could be an indication of persistent high-molecular weight $\mathrm{PF}_{\mathrm{TEG}} \mathrm{TXBT}$ homopolymer contamination, although the NMR peak broadening that is characteristic of polymeric materials makes this quantification less reliable.

The as-spun film ultraviolet-visible absorption spectra of the two amphiphilic polymers and their component homopolymers are shown in Figure 6. The addition of solubilizing hexyl side chains in the $\mathrm{PF}_{\mathrm{TEG}}$ T6BT material leads to a blue shift in absorption, a result of increased steric bulk disrupting the planarity of the conjugated backbone and decreasing the effective conjugation length. ${ }^{36}$ An increase in absorption at $450 \mathrm{~nm}$ is seen in both BCPs indicating a contribution from the P3HT block. The P3HT absorption is more pronounced in the $\mathrm{P} 3 \mathrm{HT}-b-\mathrm{PF}_{\mathrm{TEG}} \mathrm{T} 6 \mathrm{BT}$ materials, a function of the 


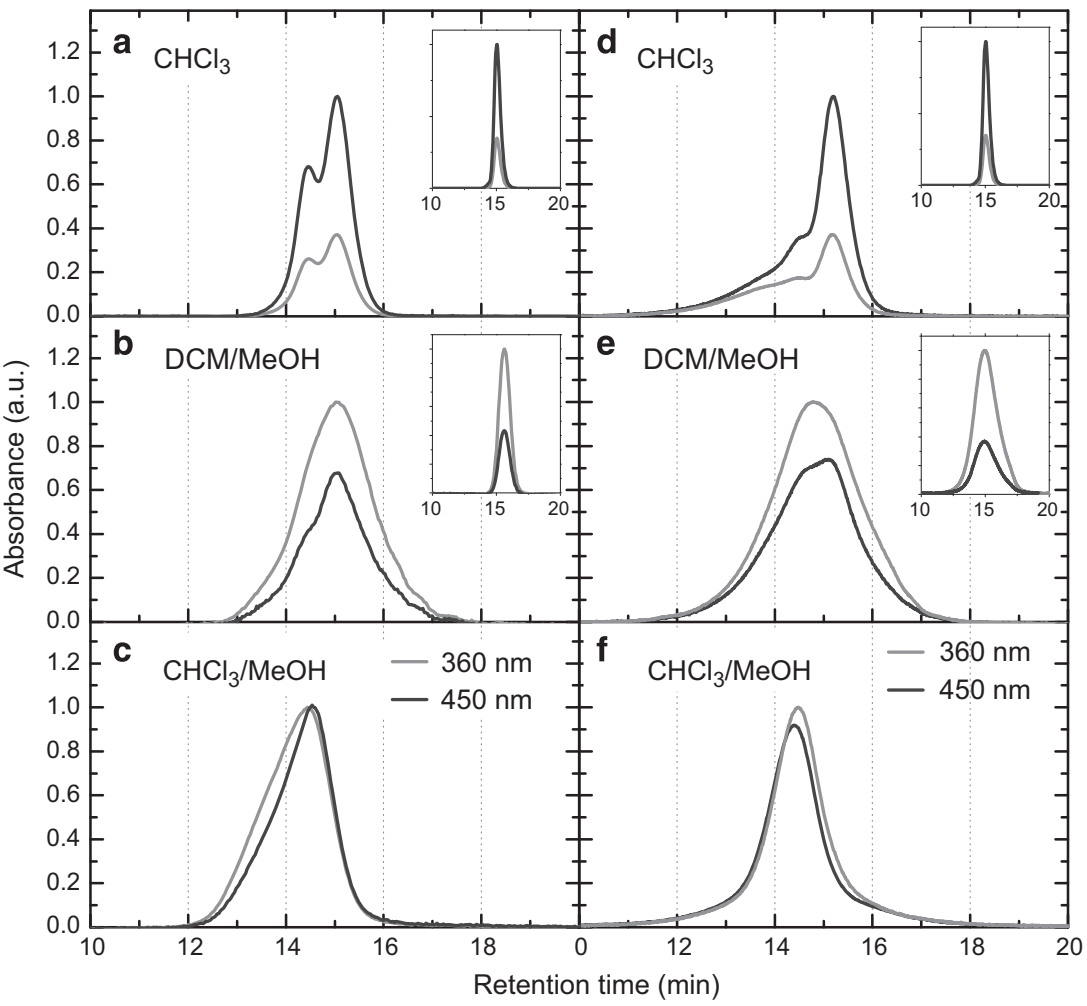

Figure $5 \mathrm{GPC}$ analysis of fractions from P3HT- $b$-PFFEG TBT (a-c) and P3HT- $b$-PFTEGT6BT (d-f). The traces of the corresponding homopolymers (P3HT in a and $d$ or $\mathrm{PF}_{\mathrm{TEG}} \mathrm{T}(\mathrm{R}) \mathrm{BT}$ in $\mathrm{b}$ and e) are given in insets for comparison. GPC, gel permeation chromatography. A full color version of this figure is available at the Polymer Journal online.

Table 2 Composition analysis of crude polymeric mixture

\begin{tabular}{lcccc}
\hline & Crude (\%) & P3HT (\%) & $P F_{T E G} T(R) B T(\%)$ & $B C P(\%)$ \\
\hline P3HT-b-PF TEGTBT T3 & 85 & 56 & 22 & 21 \\
P3HT-b-PF TEGT6BT & 82 & 36 & 31 & 32 \\
\hline
\end{tabular}

Abbreviation: BCP, block copolymer.

Crude $(\%)$ is based on the expected yield of the polymerization, component $\%$ is calculated

from fractions collected during purification.

decreased absorption coefficient of the acceptor material resulting from the additional side chains. ${ }^{37}$ The absorption onsets are given in Table 3, and indicate optical energy gaps of $1.8 \mathrm{eV}$ and $1.9 \mathrm{eV}$ for P3HT- $b$ - PF $_{\text {TEG }}$ TBT and P3HT- $b-$ PF $_{\text {TEG }}$ TBT, respectively, values that are consistent with those determined from cyclic voltammetry of films (Supplementary Information).

As seen in the spectra of pure P3HT (Figure 6, red), films of regioregular $\mathrm{P} 3 \mathrm{HT}$ are semicrystalline and show characteristic vibronic structure at 530, 560 and $610 \mathrm{~nm} .{ }^{38}$ The presence of this vibronic structure in $\mathrm{BCPs}$ incorporating $\mathrm{P} 3 \mathrm{HT}$ is an indication that the $\mathrm{P} 3 \mathrm{HT}$ is able to form crystallites, and in turn is an indication of phase separation. ${ }^{24}$ In as-spun films of both BCPs, the vibronic structure is suppressed, implying a lack of P3HT crystallinity. This suggests that either the BCPs are not able to phase-separate into domains of purity sufficient for crystallization or that phase separation occurs at the cost of crystallization, a phenonmenon seen in other BCP systems. ${ }^{29}$

Differential scanning calorimetry was employed to determine melting and crystallization temperatures and enthalpies of the BCPs. Neither of the isolated $\mathrm{PF}_{\mathrm{TEG}} \mathrm{TXBT}$ homopolymers showed melting or

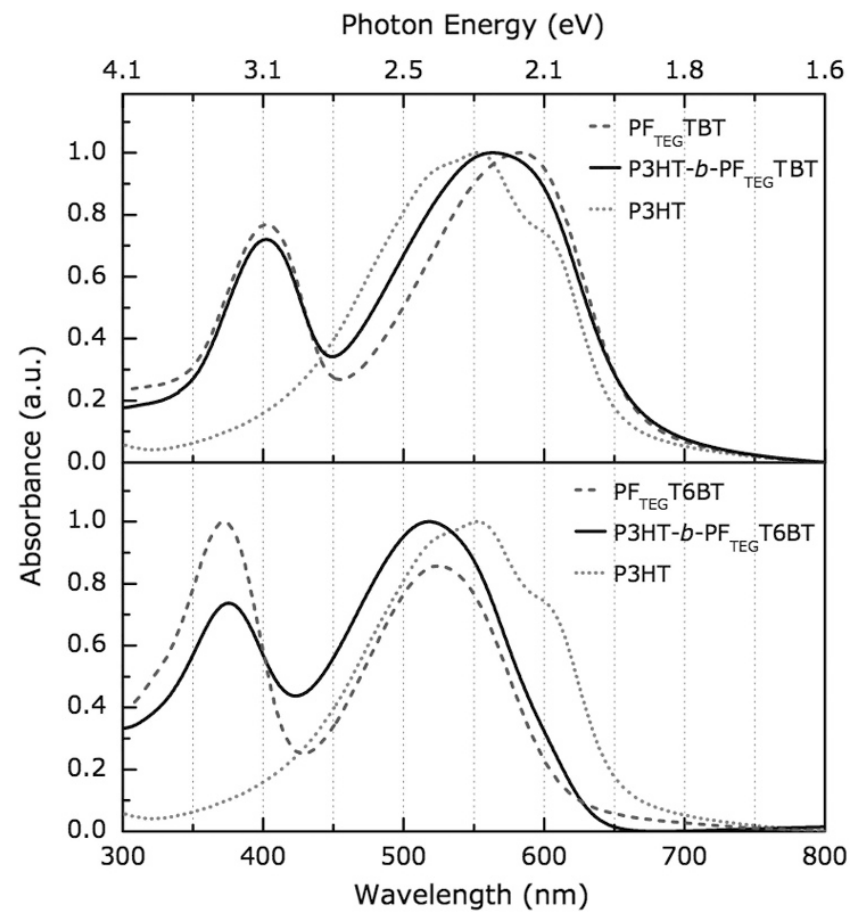

Figure 6 UV/Vis absorption spectra of block copolymers and their constituent homopolymers in as-spun film. UV, ultraviolet; Vis, visible. A full color version of this figure is available at the Polymer Journal online. 
Table 3 Optical and electrochemical energy gaps of polymers

\begin{tabular}{|c|c|c|c|c|c|}
\hline & $\lambda_{\text {onset }}(\mathrm{nm})$ & $\mathrm{E}_{g}{ }^{o p t}(\mathrm{eV})$ & HOMO (eV) & LUMO (eV) & $\mathrm{E}_{g}{ }^{e c}(\mathrm{eV})$ \\
\hline $\mathrm{PF}_{\mathrm{TEG}} \mathrm{TBT}$ & 670 & 1.85 & -5.3 & -3.5 & 1.8 \\
\hline $\mathrm{PF}_{\mathrm{TEG}} \mathrm{T}$ TBT & 618 & 2.01 & -5.4 & -3.4 & 2 \\
\hline
\end{tabular}

Abbreviations: HOMO, highest occupied molecular orbital; LUMO, lowest unoccupied molecular orbital.

$E_{\mathrm{g}}{ }^{\text {opt }}$ determined from absorption onset and $E_{\mathrm{g}}{ }^{\mathrm{ec}}$ determined from cyclic voltammetry.

Table 4 DSC analysis of block copolymer crystallinity

\begin{tabular}{|c|c|c|c|c|}
\hline & $\mathrm{T}_{m}\left({ }^{\circ} \mathrm{C}\right)$ & $\mathrm{T}_{c}\left({ }^{\circ} \mathrm{C}\right)$ & $\Delta \mathrm{H}_{m}\left(J g^{-1}\right)$ & $\mathrm{D}_{\text {РзHT }}(\%)$ \\
\hline P3HT macroinitiator & 238 & 205 & 24 & \\
\hline P3HT-b-PFTEG TBT & 220 & 181 & 1.6 & 16 \\
\hline P3HT-b-PF TEG & 209 & 163 & 2.4 & 25 \\
\hline
\end{tabular}

Abbreviation: DSC, differential scanning calorimetry.

Melting $\left(T_{\mathrm{m}}\right)$ and crystallization $\left(T_{\mathrm{c}}\right)$ temperatures, the enthalpy of melting $\left(\Delta H_{\mathrm{m}}\right)$ and degree of P3HT crystallinity $\left(D_{\mathrm{P} 3 \mathrm{HT}}\right)$.
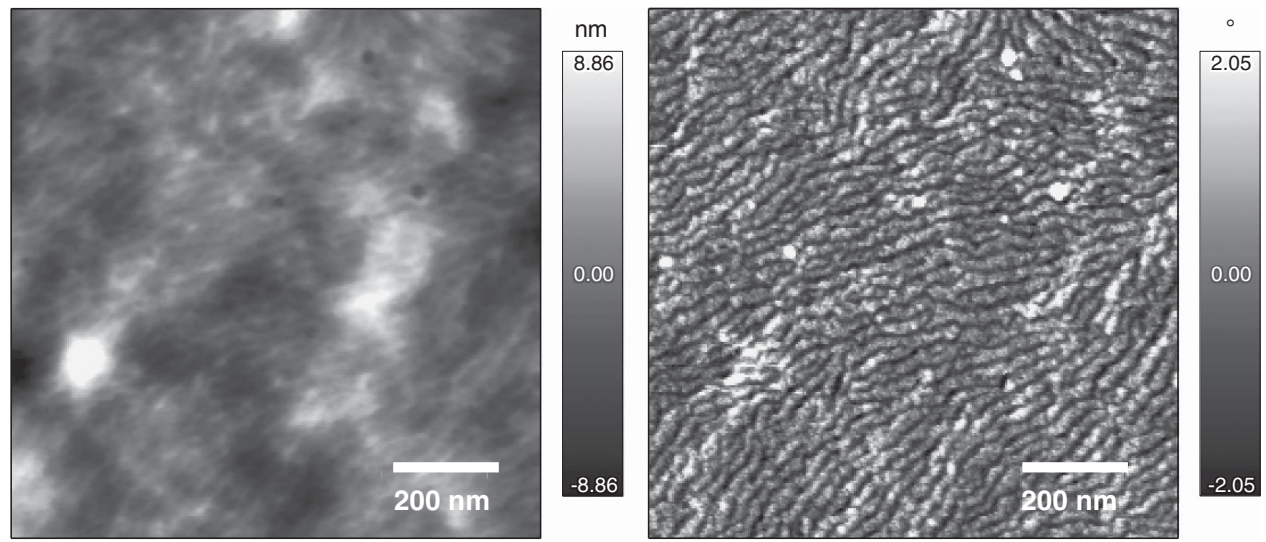

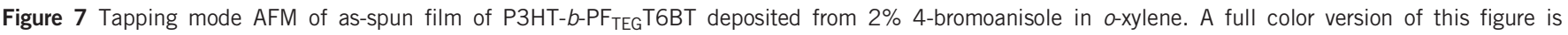
available at the Polymer Journal online.

crystallization peaks indicating their amorphous nature, which was expected from investigations of similar materials. ${ }^{24,39}$ Small melting and crystallization peaks corresponding to P3HT were seen for both BCPs (Supplementary Information). The enthalpy of melting for the isolated macroinitiator was measured and is summarized in Table 4. Using the composition of the polymers (that is, 42 and $47 \%$ P3HT) and the enthalpy of melting of the isolated macroinitiator, the degree of crystallinity of the P3HT blocks can be calculated. These measurements indicate that only $16 \%$ of the $\mathrm{P} 3 \mathrm{HT}$ in $\mathrm{P} 3 \mathrm{HT}-b-\mathrm{PF}_{\mathrm{TEG}} \mathrm{TBT}$ is able to crystallize, whereas $25 \%$ of P3HT is crystalline in P3HT- $b$ $\mathrm{PF}_{\mathrm{TEG}}$ T6BT. Interestingly, P3HT- $b$ - $\mathrm{PF}_{\mathrm{TEG}} \mathrm{TBT}$ showed an additional melting point at $170{ }^{\circ} \mathrm{C}$ that may be attributed to a different $\mathrm{P} 3 \mathrm{HT}$ polymorph present in the BCP film.

This low crystallinity in bulk measurements implies that thermal treatment may be insufficient for obtaining microphase separation. To exploit the amphiphilic nature of these BCPs, selective solvent deposition will be investigated. Previous reports have shown that 4-bromoanisole can act as a preferential solvent for PFTBT-based materials, inducing P3HT aggregation that in turn enhances phase separation and domain purity. ${ }^{40}$ Preliminary investigations of phase separation by atomic force microscopy have shown that P3HT- $b$ - $\mathrm{PF}_{\mathrm{TEG}} \mathrm{T} 6 \mathrm{BT}$ spontaneously phase separates into $30 \mathrm{~nm}$ domains when deposited from 2\% 4-bromoanisole in $o$-xylene (Figure 7). This demonstrates the potential advantages of this amphiphilic design. Further optimization and morphological investigation are underway.

\section{CONCLUSION}

In this work, two novel BCPs with potential application in OPVs were synthesized and purified. These amphiphilic BCPs are, to our knowledge, the first of their kind to employ this strategy toward enhancing microphase separation and solubility of fully conjugated donoracceptor BCPs for OPV application. The unique design allowed facile purification of these materials through the exploitation of the chemical disparity between the blocks, easily producing BCP species with a minimum of homopolymer contaminants. Although initial evaluations show an inhibition of P3HT crystallinity in bulk measurements, through careful selection of solvent deposition conditions, it is expected that microphase separation and crystallinity can be greatly enhanced in film owing to the amphiphilic nature of the polymers. The synthetic and purification strategy presented could inform future research into BCP materials, contributing to their more widespread 
implementation in OPV research. The morphological and photovoltaic properties of these new materials are currently under investigation.

\section{CONFLICT OF INTEREST}

The authors declare no conflict of interest.

\section{ACKNOWLEDGEMENTS}

This work was made possible by support from the Australian Renewable Energy Agency that funds the project grants within the Australian Centre for Advanced Photovoltaics. Responsibility for the views, information or advice expressed herein is not accepted by the Australian Government. WWHW is supported by an ARC Future Fellowship (FT130100500). This work was supported in part by funding from the German Academic Exchange Service (DAAD). Atomic force microscopy (AFM) measurements were made possible through ARC LIEF Grant LE110100161. We thank Mr Jianing Lu for his expert assistance with AFM measurements.

1 Shaheen, S. E., Brabec, C. J., Sariciftci, N. S., Padinger, F., Fromherz, T. \& Hummelen, J. C. 2.5\% efficient organic plastic solar cells. Appl. Phys. Lett. 78, 841-843 (2001).

2 Zhao, J., Li, Y., Yang, G., Jiang, K., Lin, H., Ade, H., Ma, W. \& Yan, H. Efficient organic solar cells processed from hydrocarbon solvents. Nat. Energy 1, 15027 (2016).

3 Jørgensen, M., Carlé, J. E., Søndergaard, R. R., Lauritzen, M., Dagnæs-Hansen, N. A., Byskov, S. L., Andersen, T. R., Larsen-Olsen, T. T., Böttiger, A. P. L., Andreasen, B., Fu, L., Zuo, L., Liu, Y., Bundgaard, E., Zhan, X., Chen, H. \& Krebs, F. C. The state of organic solar cells-a meta analysis. Sol. Energy Mater. Sol. Cells 119, 84-93 (2013).

4 Lucera, L., Kubis, P., Fecher, F. W., Bronnbauer, C., Turbiez, M., Forberich, K., Ameri, T., Egelhaaf, H. J. \& Brabec, C. J. Guidelines for closing the efficiency gap between hero solar cells and roll-to-roll printed modules. Energy Technol. 3, 373-384 (2015).

5 Hwang, I. \& Scholes, G. D. Electronic energy transfer and quantum-coherence in $\pi$ conjugated polymers. Chem. Mater. 23, 610-620 (2011).

6 Tamai, Y., Ohkita, H., Benten, H. \& Ito, S. Exciton diffusion in conjugated polymers: from fundamental understanding to improvement in photovoltaic conversion efficiency. J. Phys. Chem. Lett. 6, 3417-3428 (2015).

7 Verploegen, E., Mondal, R., Bettinger, C. J., Sok, S., Toney, M. F. \& Bao, Z. A. Effects of thermal annealing upon the morphology of polymer-fullerene blends. Adv. Funct. Mater. 20, 3519-3529 (2010).

8 Liu, Y., Zhao, J., Li, Z., Mu, C., Ma, W., Hu, H., Jiang, K., Lin, H., Ade, H. \& Yan, H. Aggregation and morphology control enables multiple cases of high-efficiency polymer solar cells. Nat. Commun. 5, 5293 (2014).

9 Sun, K., Xiao, Z., Lu, S., Zajaczkowski, W., Pisula, W., Hanssen, E., White, J. M. Williamson, R. M., Subbiah, J., Ouyang, J., Holmes, A. B., Wong, W. W. \& Jones, D. J. A molecular nematic liquid crystalline material for high-performance organic photovoltaics. Nat. Commun. 6, 6013 (2015).

10 Miller, S., Fanchini, G., Lin, Y. Y., Li, C., Chen, C. W., Su, W. F. \& Chhowalla, M. Investigation of nanoscale morphological changes in organic photovoltaics during solvent vapor annealing. J. Mater. Chem. 18, 306-312 (2008).

11 Tremolet de Villers, B., Tassone, C. J., Tolbert, S. H. \& Schwartz, B. J. Improving the reproducibility of P3HT:PCBM solar cells by controlling the PCBM/cathode interface. J. Phys. Chem. C 113, 18978-18982 (2009).

12 Schaffer, C. J., Palumbiny, C. M., Niedermeier, M. A., Jendrzejewski, C., Santoro, G., Roth, S. V. \& Muller-Buschbaum, P. A direct evidence of morphological degradation on a nanometer scale in polymer solar cells. Adv. Mater. 25, 6760-6764 (2013).

13 Guo, C., Lin, Y. H., Witman, M. D., Smith, K. A., Wang, C., Hexemer, A., Strzalka, J., Gomez, E. D. \& Verduzco, R. Conjugated block copolymer photovoltaics with near 3\% efficiency through microphase separation. Nano Lett. 13, 2957-2963 (2013).

14 Liu, D., Wang, Z., Zhang, S., Zheng, Z., Yang, B., Ma, W. \& Hou, J. Rational selection of solvents and fine tuning of morphologies toward highly efficient polymer solar cells fabricated using green solvents. RSC Adv. 5, 69567-69572 (2015).

15 Chen, Y., Cui, Y., Zhang, S. Q. \& Hou, J. H. Molecular design toward efficient polymer solar cells processed by green solvents. Polym. Chem. 6, 4089-4095 (2015).

16 Wong, W. H. W., Vak, D., Singh, T. B., Ren, S., Yan, C., Jones, D. J., Liawll, Lamb, R. N. \& Holmes, A. B. Ambipolar hexa-peri-hexabenzocoronene-fullerene hybrid materials. Org. Lett. 12, 5000-5003 (2010).

17 Bicciocchi, E., Chen, M., Rizzardo, E. \& Ghiggino, K. P. Synthesis of a rod-coil block copolymer incorporating PCBM. Polym. Chem. 4, 53-56 (2013).
18 Sommer, M. \& Thelakkat, M. Synthesis, characterization and application of donoracceptor block copolymers in nanostructured bulk heterojunction solar cells. Eur. Phys. J. Appl. Phys. 36, 245-249 (2006).

19 Lohwasser, R. H., Gupta, G., Kohn, P., Sommer, M., Lang, A. S., Thurn-Albrecht, T. \& Thelakkat, M. Phase separation in the melt and confined crystallization as the key to well-ordered microphase separated donor-acceptor block copolymers. Macromolecules 46, 4403-4410 (2013).

20 Gupta, G., Singh, C. R., Lohwasser, R. H., Himmerlich, M., Krischok, S., MullerBuschbaum, P., Thelakkat, M., Hoppe, H. \& Thurn-Albrecht, T. Morphology, crystal structure and charge transport in donor-acceptor block copolymer thin films. ACS Appl. Mater. Interfaces 7, 12309-12318 (2015).

21 Sommer, M., Lang, A. S. \& Thelakkat, M. Crystalline-crystalline donor-acceptor block copolymers. Angew. Chem. Int. Ed. Engl. 47, 7901-7904 (2008).

22 Segalman, R. A., McCulloch, B., Kirmayer, S. \& Urban, J. J. Block copolymers for organic optoelectronics. Macromolecules 42, 9205-9216 (2009).

23 Smith, K. A., Lin, Y. H., Mok, J. W., Yager, K. G., Strzalka, J., Nie, W. Y., Mohite, A. D. \& Verduzco, R. Molecular origin of photovoltaic performance in donor-block-acceptor all-conjugated block copolymers. Macromolecules 48, 8346-8353 (2015).

24 Sommer, M., Komber, H., Huettner, S., Mulherin, R., Kohn, P., Greenham, N. C. \& Huck, W. T. S. Synthesis, purification, and characterization of well-defined all-conjugated diblock copolymers PF8TBT-b-P3HT. Macromolecules 45, 4142-4151 (2012).

25 Bates, F. S. Polymer-polymer phase behavior. Science 251, 898-905 (1991).

26 Bates, F. S. \& Fredrickson, G. H. Block copolymers - designer soft materials. Phys. Today 52, 32-38 (1999)

27 Tu, G., Li, H., Forster, M., Heiderhoff, R., Balk, L. J., Sigel, R. \& Scherf, U. Amphiphilic conjugated block copolymers: synthesis and solvent-selective photoluminescence quenching. Small 3, 1001-1006 (2007)

28 Torabi, S., Jahani, F., Van Severen, I., Kanimozhi, C., Patil, S., Havenith, R. W. A., Chiechi, R. C., Lutsen, L., Vanderzande, D. J. M., Cleij, T. J., Hummelen, J. C. \& Koster, L. J. A. Strategy for enhancing the dielectric constant of organic semiconductors without sacrificing charge carrier mobility and solubility. Adv. Funct. Mater. 25, 150-157 (2015).

29 Ku, S. Y., Brady, M. A., Treat, N. D., Cochran, J. E., Robb, M. J., Kramer, E. J., Chabinyc, M. L. \& Hawker, C. J. A modular strategy for fully conjugated donor-acceptor block copolymers. J. Am. Chem. Soc. 134, 16040-16046 (2012).

30 Lohwasser, R. H. \& Thelakkat, M. Toward perfect control of end groups and polydispersity in poly(3-hexylthiophene) via catalyst transfer polymerization. Macromolecules 44, 3388-3397 (2011).

31 Ruzette, A.-V. \& Leibler, L. Block copolymers in tomorrow's plastics. Nat. Mater. 4 19-31 (2005).

32 Bates, F. S., Maurer, W. W., Lipic, P. M., Hillmyer, M. A., Almdal, K., Mortensen, K., Fredrickson, G. H. \& Lodge, T. P. Polymeric bicontinuous microemulsions. Phys. Rev. Lett. 79, 849-852 (1997).

33 Mok, J. W., Lin, Y.-H., Yager, K. G., Mohite, A. D., Nie, W., Darling, S. B., Lee, Y., Gomez, E., Gosztola, D., Schaller, R. D. \& Verduzco, R. Linking group influences charge separation and recombination in all-conjugated block copolymer photovoltaics. Adv Funct. Mater. 25, 5578-5585 (2015).

34 Johnson, K., Huang, Y.-S., Huettner, S., Sommer, M., Brinkmann, M., Mulherin, R., Niedzialek, D., Beljonne, D., Clark, J., Huck, W. T. S. \& Friend, R. H. Control of intrachain charge transfer in model systems for block copolymer photovoltaic materials. J. Am. Chem. Soc. 135, 5074-5083 (2013)

35 Mulherin, R. C., Jung, S., Huettner, S., Johnson, K., Kohn, P., Sommer, M., Allard, S., Scherf, U. \& Greenham, N. C. Ternary photovoltaic blends incorporating an all-conjugated donor-acceptor diblock copolymer. Nano Lett. 11, 4846-4851 (2011).

36 George, Z., Kroon, R., Gehlhaar, R., Gbabode, G., Lundin, A., Hellstrom, S., Muller, C., Geerts, Y., Heremans, P. \& Andersson, M. R. The influence of alkoxy substitutions on the properties of diketopyrrolopyrrole-phenyl copolymers for solar cells. Materials 6 3022-3034 (2013).

37 Yue, W., Zhao, Y., Shao, S. Y., Tian, H. K., Xie, Z. Y., Geng, Y. H. \& Wang, F. S. Novel NIR-absorbing conjugated polymers for efficient polymer solar cells: effect of alkyl chain length on device performance. J. Mater. Chem. 19, 2199-2206 (2009).

38 Brown, P. J., Thomas, D. S., Kohler, A., Wilson, J. S., Kim, J. S., Ramsdale, C. M., Sirringhaus, H. \& Friend, R. H. Effect of interchain interactions on the absorption and emission of poly(3-hexylthiophene). Phys. Rev. B 67, 064203 (2003).

39 McNeill, C. R., Halls, J. J. M., Wilson, R., Whiting, G. L., Berkebile, S., Ramsey, M. G., Friend, R. H. \& Greenham, N. C. Efficient polythiophene/polyfluorene copolymer bulk heterojunction photovoltaic devices: device physics and annealing effects. Adv. Funct. Mater. 18, 2309-2321 (2008).

40 Liu, X., Huettner, S., Rong, Z., Sommer, M. \& Friend, R. H. Solvent additive control of morphology and crystallization in semiconducting polymer blends. Adv. Mater. 24, 669-674 (2012).

Supplementary Information accompanies the paper on Polymer Journal website (http://www.nature.com/pj) 